\title{
DERECHO INTERNACIONAL, NUDOS Y DESAFÍOS. IMPLICANCIA PARA EL EJERCICIO DE LOS DERECHOS TERRITORIALES DEL PUEBLO MAPUCHE
}

\author{
Nancy Adriana Yáñez Fuenzalida ${ }^{197}$
}

\begin{abstract}
Estándares internacionales en materia de propiedad indígena sobre los territorios y las tierras ancestrales
\end{abstract}

El Convenio 169 sobre Pueblos Indígenas y Tribales de la Organización Internacional del Trabajo (OIT), en adelante el Convenio 169, es el tratado internacional que regula los derechos de pueblos indígenas, ratificado por Chile y vigente en nuestro país desde septiembre del año 2009. Como garantías del derecho de propiedad y posesión ancestral de los pueblos indígenas, el Convenio 169 enfatiza el deber de los Estados de adoptar todas "[...] las medidas que sean necesarias para determinar las tierras que los pueblos interesados ocupan tradicionalmente y garantizar la protección efectiva de sus derechos de propiedad y posesión" (artículo 14.2). De la misma forma, subraya la obligación de los Estados de instituir "[...] procedimientos adecuados en el marco del sistema jurídico nacional para solucionar las reivindicaciones de tierras formuladas por los pueblos interesados" (artículo 14.3).

La interpretación que los órganos de supervisión de la OIT han hecho de estas garantías ha determinado que los derechos de propiedad y posesión que regula el artículo 14 antes citado, no solo se refieren a aquellas tierras sobre las cuales los pueblos indígenas tienen propiedad legal u oficialmente reconocida, sino también sobre aquellas de ocupación ancestral, aunque no tengan título de dominio sobre ellas. Así lo ha establecido la Comisión de Expertos en Aplicación de Convenios y Recomendaciones de la OIT (CEACR), disponiendo que el establecimiento de los derechos de los pueblos indígenas sobre sus tierras o territorio se basa en la ocupación y en el uso

197 Universidad de Chile quemchiyanez@gmail.com. 
tradicional, y no en el eventual reconocimiento o registro legal oficial de la propiedad de la tierra por parte de los Estados ${ }^{198}$. De igual modo, la CEACR ha establecido que el derecho fundado en la ocupación de la tierra es un principio rector del Convenio: "si los pueblos indígenas no pudieran hacer valer la ocupación tradicional como fuente de derechos de propiedad y de posesión, el artículo 14 del Convenio se vaciaría de contenido [...]. La Comisión es consciente de la complejidad de plasmar este principio en la legislación, así como de diseñar procedimientos adecuados, pero subraya, al mismo tiempo, que el reconocimiento de la ocupación tradicional como fuente de derechos de propiedad y posesión mediante un procedimiento adecuado, es la piedra angular sobre el que reposa el sistema de derechos sobre la tierra establecido por el Convenio. El concepto de ocupación tradicional puede ser reflejado de diferentes maneras en la legislación nacional, pero debe ser aplicado"199.

Por otra parte, la Declaración de la Naciones Unidas sobre los Derechos de los Pueblos Indígenas (DNUDPI) hace un reconocimiento explícito al derecho a poseer, utilizar, desarrollar y controlar no solo las tierras, sino también los territorios y recursos que poseen en razón de la propiedad tradicional y otra forma tradicional de ocupación (art. 26.1). Más aún, establece que los pueblos indígenas tienen derecho a que las tierras, territorios y recursos naturales que tradicionalmente hayan poseído u ocupado, les sean restituidos y/o sean compensados cuando hayan sido confiscados o tomados sin su consentimiento (Aylwin et. al, 2013).

La jurisprudencia de la Corte Interamericana de Derechos Humanos, en adelante la Corte IDH, ha establecido las siguientes obligaciones estatales en materia de derechos territoriales: i) deber de reconocer que la posesión tradicional de las tierras indígenas por parte de los pueblos indígenas y tribales tiene efectos jurídicos homologables al título de dominio pleno que otorga el Estado e incluye el concepto de territorios; ii) deber de reconocer que dicha posesión tradicional otorga a los pueblos indígenas el derecho a exigir el reconocimiento oficial de la propiedad y su registro, y el derecho a no ser trasladados; iii) deber de proceder a la demarcación, delimitación y titulación de las tierras indígenas; iv) deber de restituir, cuando corresponda, las tierras tradicionales a la comunidades, cuando por causas ajenas a su voluntad hayan salido de sus tierras tradicionales o perdido la posesión de las mismas y estas se encuentran en manos de terceros; v) deber de otorgar tierras alternativas de la misma extensión y calidad que las perdidas cuando, excepcionalmente, la restitución no fuera posible, las que deben quedar acordadas libremente con las comunidades y sus legítimos representantes; vi) deber de indemnizar plenamente a las personas trasladadas y reubicadas como consecuencia de cualquier daño que hayan sufrido a causa del desplazamiento (Steiner CH. y Fuchs M. Eds., 2019) ${ }^{200}$.

Tratándose de tierras indígenas no tituladas, la obligación internacional del Estado es demarcar y titular los territorios indígenas para proveer certeza jurídica sobre el dominio ancestral indígena. Previo a la demarcación y titulación de estos territorios, así lo ha consignado la Corte

198 Conferencia Internacional del Trabajo, CEACR, 2003, 73.ㄹa sesión, Observación, Perú: párrafo 7.

199 Conferencia Internacional del Trabajo, CEACR, 2009: p. 742.

200200 STEINER CH. y FUCHS M. Eds., 2019 2a. Ed.: 632 a 634. 


\section{Capítulo 7. Página 140}

IDH $^{201}$, el Estado se debe abstener de realizar cualquier tipo de actos que puedan afectar la integridad de los territorios indígenas ${ }^{202}$.

Recientemente, la Corte IDH consolidó su jurisprudencia respecto a las obligaciones estatales en materia de propiedad indígena ${ }^{203}$, en los siguientes términos:

a) deslindar las tierras indígenas de otras y otorgar título colectivo de las tierras a las comunidades; b) abstenerse de realizar actos que puedan llevar a que los agentes del propio Estado o terceros que actúen con su aquiescencia o su tolerancia, afecten la existencia, el valor, el uso o el goce de su territorio; y c) a su vez, garantizar el derecho de los pueblos indígenas de controlar y usar efectivamente su territorio y recursos naturales, así como de ser propietarios de su territorio sin ningún tipo de interferencia externa de terceros ${ }^{204}$.

Como ha sido expresado precedentemente, la titulación y demarcación deben implicar el uso y goce pacífico de la propiedad ${ }^{205}$, ello supone que el derecho de propiedad colectiva indígena debe estar libre de la interferencia del Estado y terceros, incluso de terceros de buena fe, aun cuando estos pertenezcan a grupos vulnerables que dependan de la tierra para su subsistencia, como sería el caso de pequeños campesinos.

La Corte IDH ha determinado como estándar exigible en el proceso de titulación de tierras indígenas, la pertinencia cultural del título que reconoce la propiedad y posesión colectiva indígena sobre sus tierras ancestrales, lo que implica que este sea idóneo a efectos de reconocer las "[...] versiones específicas del derecho al uso y goce de los bienes, dadas por la cultura, usos, costumbres y creencias de cada pueblo"206.

Los derechos territoriales indígenas incluyen los derechos a un medio ambiente sano, a la alimentación adecuada, al agua y a participar en la vida cultural, conforme el artículo 26 de la Convención ${ }^{207}$. La Corte IDH, en febrero del presente año, haciendo un análisis sistemático entre la Convención y la Carta de la Organización de los Estado Americanos (Carta de la OEA), reconoce que el derecho al medio ambiente sano se entiende incluido en el artículo 26 de la Convención y que dimana de la obligación de los Estados de alcanzar el "desarrollo integral" de sus pueblos, conforme lo establecen los artículos 30, 31, 33 y 34 de la Carta de la OEA ${ }^{208}$, y precisa que sus contenidos normativos están en su Opinión Consultiva OC-23/17, relevando que se trata de un derecho autónomo que protege los componentes del ambiente, tales como bosques, mares, ríos y otros (Yáñez, 2020). Protege la naturaleza y sus componentes, como intereses/bienes jurídicos en sí mismos. Pese a que el derecho al medio ambiente es un derecho autónomo, la Corte IDH reconoce

201 Corte IDH, Caso del Pueblos Saramaka Vs. Surinam, Sentencia del 28 de noviembre de 2007, Excepciones Preliminares, Fondo, Reparaciones y Costas, Serie C N²172, párr. 194.

202 Corte IDH, Caso del Pueblo Saramaka Vs. Surinam, Sentencia de 12 de agosto de 2008, Interpretación de la sentencia de excepciones preliminares, Fondo, Reparaciones y Costas, Serie C N 185, párr. 196.

203 Corte IDH, Caso Comunidades Indígenas miembros de la Asociación Lhaka Honhat con Argentina, sentencia de 6 de febrero de 2020, Fondo, Reparaciones y Costas.

204 Ib., párr. 98.

205 Ib., párr. 96.

206 Caso del pueblo indígena Xucurú y sus miembros vs. Brasil, sentencia de 5 de febrero de 2018, Excepciones Preliminares, Fondo, Reparaciones y Costas, Serie $\mathrm{C} \mathrm{N}^{\circ} 346$, párr. 115. Caso Comunidades Indígenas miembros de la Asociación Lhaka Honhat con Argentina, párr. 279.

207 Ib., párr. 201.

208208 Ib., párr. 202. 
que otros derechos humanos puedan ser vulnerados como consecuencia de daños ambientales $y$, de igual modo, deben ser salvaguardados ${ }^{209}$.

La Corte IDH ha dispuesto que el Estado tiene respecto a este derecho la obligación de respeto y, asimismo, la obligación de garantía, de modo tal que prevenga vulneraciones de terceros del medio ambiente indígena (Yáñez, 2020). Se consigna que esta obligación de prevenir daños ambientales forma parte del derecho internacional consuetudinario (Yáñez, 2020). Se establece que los estándares exigibles al Estado para la aplicación del principio de prevención, frente a actividades potencialmente dañosa al medio ambiente son: i) regular; ii) supervisar y fiscalizar; iii) requerir y aprobar estudios de impacto ambiental; iv) establecer planes de contingencia; y v) mitigar en casos de ocurrencia de daño ambiental ${ }^{210}$. La debida diligencia supone hacerse cargo de la circunstancia que las problemáticas ambientales pueden afectar de modo diferenciado a pueblos, grupos y personas en condición de vulnerabilidad, como los pueblos indígenas, quienes dependen para su economía y supervivencia de la integridad de los recursos ambientales que configuran su hábitat ${ }^{211}$. El derecho a la alimentación debe garantizarse conforme a los estándares establecidos en la Observación General 12 del Comité de Derechos Económicos, Sociales y Culturales (DESC), el que señaló que el "contenido básico" del derecho a la alimentación comprende "la disponibilidad de alimentos en cantidad y calidad suficientes para satisfacer las necesidades alimentarias de los individuos, sin sustancias nocivas, y aceptables para una cultura determinada", y "la accesibilidad de esos alimentos en formas que sean sostenibles y que no dificulten el goce de otros derechos humanos" ${ }^{212}$. La Corte IDH releva los componentes culturales del derecho y su incidencia en la conceptualización de los estándares de "adecuación" y "seguridad alimentaria" que son propios del derecho ${ }^{213}$. También ha sido reconocido el derecho al agua ${ }^{214} \mathrm{y}$, al igual que en lo que refiere al derecho a la alimentación, se han fijado los estándares de conformidad a lo establecido por el Comité DESC en la Observación General $\mathrm{N}^{\circ} 15^{215}$. Finalmente, la jurisprudencia interamericana, efectuando un análisis sistemático de los derechos antes mencionados y su interdependencia ${ }^{216}$, precisa que estos derechos (al agua, a la alimentación y a participar en la vida cultural), son particularmente vulnerables a las afectaciones ambientales (Yáñez, 2020). De la misma forma, establece que hay una relación necesaria entre identidad cultural y desarrollo integral de los pueblos, precisando que el derecho al desarrollo con identidad protege los rasgos distintivos que caracterizan a un grupo social, sin que ello implique negar el carácter histórico, dinámico y evolutivo de la cultura"217.

215 Comité DESC. Observación General 15. El derecho al agua (artículos 11 y 12 del Pacto Internacional de Derechos Económicos, Sociales y Culturales).

216 Corte IDH, caso Lhaka Honaht Vs. Argentina, véase, epígrafe B.1.2 Interdependencia entre los derechos a un ambiente sano, a la alimentación adecuada, al agua y a la identidad cultural y especificidades en relación con pueblos indígenas. 217 Ib., párr. 240. 


\section{Capitulo 7. Página 142}

Otro ámbito relevante del desarrollo jurisprudencial interamericano para la salvaguarda de los derechos territoriales indígenas es en materia de consulta. La Corte IDH se ha pronunciado específicamente sobre el estándar de consulta, estableciendo que la obligación del Estado de consultar a los pueblos indígenas es un principio de derecho internacional ${ }^{218}$. Así, ha determinado que el Estado está obligado a consultar acerca de seis asuntos:

i) el proceso de delimitación y demarcación del territorio comunal; ii) el reconocimiento legal de la capacidad jurídica colectiva de las organizaciones representativas indígenas;

iii) el proceso de adopción de medidas legislativas, administrativas o de otra índole que incidan en el reconocimiento, protección y garantía de los derechos colectivos indígenas; iv) el proceso de adopción de medidas legislativas, administrativas o de otra índole que sean necesarias para reconocer y garantizar el derecho de los pueblos indígenas a ser efectivamente consultados, de conformidad con sus tradiciones y costumbres; v) sobre los resultados de los estudios previos de impacto social y ambiental; y vi) en relación con cualquier restricción a los derechos de propiedad de los pueblos indígenas, particularmente respecto de planes de desarrollo o inversión dentro o que afecten sus territorios ${ }^{219}$.

\section{Las brechas de implementación de los estándares internacionales en materia de derechos territoriales indígenas en Chile}

Los derechos territoriales indígenas en Chile están regulados por los tratados internacionales de derechos humanos ratificados por Chile y vigentes ${ }^{220}$, la Ley № 19.253 sobre protección, fomento y desarrollo de los indígenas, la Ley № 20.249 sobre Reconocimiento del Territorio Marítimo de los Pueblos Originarios y La Ley № 19.300 sobre Bases del Medio Ambiente.

Los derechos indígenas a la tierra están reconocidos en la Ley № 19.253 sobre Protección, Fomento y Desarrollo de los Indígenas, en adelante la Ley Indígena, que establece que la tierra es el fundamento principal de la existencia y cultura de las "etnias" indígenas, omitiendo el reconocimiento de los pueblos indígenas como "pueblos". La Ley Indígena dispone como uno de los deberes del Estado y la sociedad en general, proteger las tierras de las etnias indígenas, velar por su adecuada explotación, su equilibrio ecológico y propender a su ampliación (artículo 1). Identifica las tierras indígenas, incorporando en esta categoría aquellas que las personas o comunidades indígenas ocupan, sea en propiedad o posesión, y que provienen de toda clase de títulos emanados del Estado. Considera a futuro aquellas que sean declaradas por los tribunales como pertenecientes a indígenas y las que los indígenas y sus comunidades reciban a futuro a título gratuito del Estado. También identifica como tierras indígenas (ancestrales) las que históricamente han ocupado y poseen personas o comunidades indígenas, caso en que se requiere, para que sean consideradas como tales, que sean inscritas en el registro de tierras de CONADI (artículo 12). Así, el artículo $12 \mathrm{~N}^{\circ} 2$ dispone que son tierras indígenas: "Aquellas que históricamente han ocupado y poseen las personas o

218 Corte IDH, Caso Pueblo Indígena Kichwa de Sarayaku Vs. Ecuador. Fondo y Reparaciones. Sentencia de 27 de junio de 2012 , Serie C N² 245, párrs.165 y ss.

219 Corte IDH, Caso Saramaka con Surinam, 2008, párr. 16. 220 Artículo 5, inciso 2, Constitución Política de la República. 


\section{Capitulo 7. Página 143}

comunidades mapuche, aymara, rapa nui o pascuenses, atacameñas, quechuas, coya, kawésqar y yámana, siempre que sus derechos sean inscritos en el Registro de Tierras Indígenas que crea esta ley, a solicitud de las respectivas comunidades o indígenas titulares de la propiedad". CONADI abriría un registro de tierras en el que se inscribirían las tierras de que trata el artículo 12 (artículo 15).

La Ley № 19.253 procuró poner término al proceso divisorio de las comunidades reduccionales mapuche, disponiendo que estas solo podían ser divididas por la mayoría absoluta de quienes tuviesen derechos en ellas. Además, reconoció como tierras indígenas a las tierras individuales o colectivas que los indígenas estuviesen ocupando en ese momento en propiedad o posesión proveniente de los títulos utilizados por el Estado en el pasado, así como a aquellas que en el futuro fuesen declaradas como tales por la justicia o a raíz de un título gratuito del Estado. La ley también les brindó protección con el objeto de impedir que estas pudiesen ser enajenadas, gravadas y traspasadas a no indígenas, como había ocurrido en el pasado. Finalmente, la ley promovió la ampliación de las tierras para los indígenas y sus comunidades, fundamentalmente vía mercado y a través del traspaso de tierras fiscales a través de un Fondo de Tierras y Aguas creado para estos efectos. En cuanto a la división de las tierras comunitarias provenientes de títulos de merced, la ley establece que se requerirá de solicitud formal al juez competente de la mayoría absoluta de los titulares de derechos hereditarios en ella (artículo 16), y que las tierras resultantes de la división de comunidades serían indivisibles, aun en el caso de sucesión por causa de muerte (artículo 17).

Además, la Ley Indígena otorga protección jurídica a dichas tierras indígenas, de propiedad individual o colectiva, estableciendo que, "por exigirlo el interés nacional", las tierras indígenas no podrán ser enajenadas, embargadas, gravadas ni adquiridas por prescripción, salvo entre comunidades o personas de una misma etnia. Dispone que tampoco podrán ser arrendadas en el caso de las tierras de comunidades y solo por un plazo no superior a cinco años en el caso de las tierras de propiedad individual (artículo 13). Establece, además, que solo podrán permutarse por tierras de no indígenas.

Se establece como mecanismo para proveer la ampliación de las tierras indígenas el Fondo de Tierras y Aguas. En lo sustancial, establece que dicho fondo será administrado por CONADI con el objeto de: a) otorgar subsidios para la adquisición de tierras por personas y comunidades indígenas cuando la superficie de que dispongan sea insuficiente; b) financiar mecanismos que permitan la solución de problemas de tierras, en especial con motivo del cumplimiento de resoluciones o transacciones judiciales o extrajudiciales que recaigan sobre tierras indígenas; y c) financiar la constitución, regularización o compra de derechos de agua o financiar obras destinadas a obtener este recurso (artículo 20). Dispone que los recursos de este fondo estarán compuestos por aquellos que anualmente establezca la Ley de Presupuesto con este objeto, además de aquellos provenientes de la cooperación internacional, aportes de particulares, organismos públicos y privados, devoluciones contempladas en el artículo 22 de esta ley, las rentas que devenguen los bienes del Estado, así como las tierras, predios o propiedades que reciba del Estado (artículo 21). Las tierras no indígenas y aguas adquiridas con este fondo no podrán ser enajenadas por 25 años desde su inscripción (artículo 23).

Como se observa, el mecanismo que provee la ley para responder a la demanda de tierras indígenas consiste en un fondo que permite adquirir tierras en el mercado 


\section{Capitulo 7. Página 144}

inmobiliario, no garantiza la restitución de las tierras históricas y permite liberar las tierras adquiridas con este fondo, autorizando su enajenación una vez que hayan transcurrido 25 años desde su adquisición por el Estado para restituirla a los indígenas (Yáñez, 2017a). Si bien el Fondo de Tierras y Aguas se ha visto incrementado sistemáticamente entre los años 1994 y 2017, con un crecimiento real de 16,5 veces, lo cierto es que esto no ha tenido un impacto sustancial en la restitución de tierras indígenas, toda vez que el mecanismo genera condiciones de especulación y alzas en los precios. Este incremento en el valor de las tierras se ha exacerbado en momentos de conflictos $\mathrm{y}$, al mismo tiempo, ha sido un incentivo para aumentar la conflictividad social, favoreciendo a los particulares que usufructúan de la plusvalía que genera la disputa por la restitución de las tierras de propiedad ancestral indígena (Donoso, 2017).

No cabe duda que esta normativa no se ajusta a los estándares internacionales y, en particular, a las normas del Convenio 169, según lo ha representado la propia OIT a través de su Comisión de Expertos (CEACR). En efecto, la CEACR en sus observaciones al Estado de Chile el año 2013, ha señalado: "Teniendo en cuenta la persistencia de una situación que no cumple con el Convenio, la Comisión reitera su pedido al Gobierno para que informe en su próxima memoria de manera detallada sobre la adecuación con el Convenio del mecanismo de regularización de tierras y su procedimiento de solución de conflictos. La Comisión espera poder examinar informaciones que permitan comprobar que se tuvieron en cuenta las preocupaciones expresadas por las organizaciones sindicales y los Pueblos Indígenas en las observaciones comunicadas en 2010 y se reconoció a los Pueblos Indígenas el derecho de propiedad y de posesión sobre las tierras que consagran los Artículos 13 y 14 del Convenio"221.

\section{La lucha del Pueblo Mapuche por la restitución del territorio y la sanción del derecho internacional a la criminalización como respuesta estatal}

Desde la ocupación del territorio mapuche por parte del Estado de Chile, el Pueblo Mapuche no ha claudicado en su lucha por recuperar las tierras usurpadas. Primero, accionando ante los Juzgados de Indios (1930-1961) y, posteriormente, recuperando de facto sus tierras en el marco de la reforma agraria (Correa et $A L$., 2003). En la actualidad, sus demandas continúan insatisfechas y sus acciones para la recuperación de esas tierras han sido criminalizadas o reprimidas por el Estado de Chile mediante el uso excesivo y abusivo de la fuerza, generando como resultado el encarcelamiento, la violencia y el asesinato de líderes y comuneros mapuche (Yáñez, 2017b).

La Corte IDH, sentencia de 29 de mayo de 2014222, condenó al Estado chileno por violar derechos fundamentales garantizados en la Convención Americana a ocho miembros del Pueblo Mapuche condenados por Ley Antiterrorista, caso Norin Catriman y otros vs. Chile (Yáñez, 2017b).

221 Conferencia Internacional del Trabajo, sesión diciembre de 2013, publicado en febrero de 2014: 908.

222 Caso Norin Catriman y otros (dirigentes, miembros y activistas del pueblo indígena mapuche) vs. Chile, sentencia de 29 de mayo de 2014, Fondo, Reparaciones y Costas, Serie C N²79. 
En la sentencia, la Corte concluyó que el Estado de Chile violó el principio de legalidad y el derecho a la presunción de inocencia en perjuicio de las ocho víctimas de este caso por haber mantenido vigente y aplicado el artículo 1 de la Ley $\mathrm{N}^{\circ} 18.314$ que contenía una presunción legal del elemento subjetivo del tipo terrorista ${ }^{223}$. La Corte determinó que en la fundamentación de las sentencias condenatorias se utilizaron razonamientos que denotan estereotipos y prejuicios, lo cual configuró una violación del principio de igualdad y no discriminación, y el derecho a la igual protección de la ley ${ }^{224}$. El fallo hace un llamado de atención por la existencia de una legislación que no garantiza el derecho al debido proceso, poniendo especial atención y haciendo recomendaciones en relación al uso de testigos con identidad reservada que no garantizan el derecho a la contra-interrogación, ordenando se modifique esta legislación. En síntesis, la Corte señaló que el Estado de Chile violó el principio de legalidad y de presunción de inocencia, el principio de igualdad ante la ley ygarantías judiciales. Además de vulnerar el derecho a defensa, a la libertad personal, libertad de pensamiento y expresión, el derecho a recurrir un fallo ante un tribunal superior y, por último, violó los derechos políticos de las víctimas ${ }^{225}$.

Cabe tener presente que, respecto a la noción de terrorismo aplicada en este caso, acorde a lo preceptuado en el informe del relator Ben Emerson, es forzoso concluir que en Chile no se han seguido las directrices internacionales (Resolución 1566/2004) y convenciones internacionales ${ }^{226}$.

Diversos órganos internacionales han explicitado en sus recomendaciones que el Estado de Chile debe abstenerse de aplicar esta legislación a los miembros del Pueblo Mapuche. En esta línea se ha pronunciado el Comité de Derechos Humanos ONU en sus observaciones finales sobre el sexto informe periódico de Chile, 13 de agosto de 2014, (CCPR/C/ CHL/CO/6), párr. 7, estableciendo:

- El Estado parte debe reformar la Ley Antiterrorista y adoptar una definición clara y precisa de los delitos de terrorismo para asegurar que las actividades que realizan los agentes del orden en el marco de la lucha contra el terrorismo no estén dirigidas a determinadas personas por su origen étnico o cualquier motivo social o cultural.

- Asimismo, debe asegurar que las garantías procesales, contenidas en el artículo 14 del Pacto, sean respetadas. El Comité insta al Estado parte a abstenerse de aplicar la Ley Antiterrorista en contra de los mapuche.

Lo propio ha señalado el Comité para la Eliminación de la Discriminación Racial ONU, en sus observaciones finales sobre los informes periódicos 19a a 21ํ de Chile, 30 de agosto de 2013, CERD/C/CHL/CO/19-21), párr. 14, Manifestando que se asegure que la Ley Antiterrorista no sea aplicada a miembros de la comunidad mapuche por actos de demanda social (Yáñez, 2017b).

223 Ibídem, párr. 168 a 177.

224 lb., párrs. 223 a 228 y 230

225 lb., párrs. 374 y 383.

226 Resolución 1566 (2004)". Cfr. UN Doc. A/HRC/16/51, 21 de diciembre de 2010, Consejo de Derechos Humanos, Informe del Relator Especial sobre la promoción y protección de los derechos humanos y las libertades fundamentales en la lucha contra el terrorismo, Sr. Martin Scheinin, Diez esferas de mejores prácticas en la lucha contra el terrorismo, párrs. 23, 27 y 28. 


\section{Capitulo 7. Página 146}

En el marco del Examen Periódico Universal (EPU) 2018, se reiteraron estas recomendaciones. Específicamente, se insta al Estado a "abstenerse de aplicar la Ley Antiterrorista en el contexto de protestas sociales de los pueblos mapuche que buscan reclamar sus derechos". El Estado de Chile no aceptó esta recomendación ${ }^{227}$. Chile no acepta la recomendación signada con el número 125.241, argumentando que "el proyecto de ley que modifica la legislación antiterrorista nacional no contempla crear excepciones a la generalidad de su aplicación"228. Por otra parte, la Corte IDH en el caso Norin Catriman vs. Chile constata que varios órganos y expertos internacionales han afirmado que Chile no ha resuelto de forma efectiva las causas que dan lugar a la protesta social mapuche, evidenciando esta como la razón fundamental de la protesta mapuche ${ }^{229}$.

Así también lo consignó el Relator Especial sobre la promoción y protección de derechos humanos en la lucha contra el terrorismo, Ben Emmerson, mencionado supra, en su visita a Chile en julio de 2013 y sostuvo: "que cuando el Estado no cumple con las expectativas de solucionar las reivindicaciones territoriales indígenas mapuche, permanece latente el riesgo de que las protestas sociales escalen de nivel. En este sentido, resulta prioritario que el Estado garantice una atención y solución adecuada y efectiva a tales reclamaciones para proteger y garantizar tanto los derechos del pueblo indígena como los del resto de los miembros de la sociedad en dichas regiones" 230 .

\section{Los desafíos del derecho internacional: exigibilidad de las sentencias internacionales en el derecho interno a partir del caso Norin Catriman y otros vs. Chile}

El gran desafío que enfrenta el derecho internacional de los derechos humanos es su exigibilidad en el derecho interno y su cabal cumplimiento por los Estados. La situación se ha planteado paradigmáticamente en el caso Norin Catriman y otros vs. Chile, que reseñamos en el párrafo precedente. Específicamente, a propósito del cumplimiento íntegro de las medidas de reparación decretadas por la Corte IDH en el párrafo 422, punto dispositivo décimo sexto de la sentencia, de 29 de mayo de 2014. Sobre el proceso de cumplimiento de la sentencia de parte del Estado de Chile, es necesario consignar lo siguiente:

1. La Corte IDH notificó con fecha 21 de diciembre de 2018, la resolución de supervisión del cumplimiento de la sentencia, antes citada.

2. En su comunicación, la Corte IDH declara que el Estado de Chile ha dado cumplimiento parcial a la medida de reparación ordenada en el punto dispositivo antes citado y que dice relación con dejar sin efecto, en todos sus extremos, las sentencias penales condenatorias emitidas en contra de las ocho víctimas del caso.

227 A/HRC/41/6/Add.1. Informe del Grupo de Trabajo sobre el Examen Periódico Universal Chile, adición, observaciones sobre las conclusiones y/o recomendaciones, compromisos voluntarios y respuestas del Estado examinado.

228 Ibídem, párr. 35.

229 Caso Norin Catriman y otros vs. Chile, párrs. 79 a 85.

230 [en línea] http://acnudh.org/informe-del-relator-especial-sobre-la-promocion-y-proteccion-de-los-derechos-huma- nos-y-laslibertades-fundamentales-en-la-lucha-contra-el-terrorismo/. Consultado el 28 de enero de 2018. 


\section{Capítulo 7. Página 147}

3. La Corte IDH instó al Estado de Chile para que adopte, a la brevedad posible, todas las medidas judiciales, administrativas o de cualquier índole para cumplir con los aspectos pendientes de cumplimiento.

En base a estos antecedentes, la Dirección de Derechos Humanos del Ministerio de Relaciones Exteriores, RR.EE (DDEHU) Oficio Púb. Nº01168 de 5 de febrero de 2019, solicitó a la Excma. Corte Suprema que informe respecto a las medidas judiciales adoptadas o susceptibles de ser adoptadas para dar cabal cumplimiento a la sentencia, de modo que se deje sin efecto en todos sus extremos las sentencias pronunciadas en contra de las ocho víctimas en las causas RUC 0100086503-6, RIT 2-2003 y RUC 0100086954-2, RIT 21-2004 del Tribunal del Juicio Oral en lo Penal de Angol. La problemática jurídica planteada fue determinar si un fallo de la Corte IDH puede dejar sin efecto, esto es, anular en todos sus extremos, los fallos de los tribunales superiores de justicia de los países miembros del sistema, en este caso Chile.

Para responder a estas cuestiones jurídicas es necesario pronunciarse, primero, respecto a las potestades jurisdiccionales de la Corte IDH, naturaleza jurídica de la sentencia y la obligación de cumplimiento. Al respecto sostenemos lo siguiente:

- El sistema internacional de protección de derechos humanos es complementario del ordenamiento jurídico interno en materia de protección y garantía de dichos derechos, lo que se expresa, fundamentalmente, en la incorporación de los tratados internacionales de derechos humanos ratificados por Chile y vigentes a la Constitución. Conforme al artículo 5 inciso 2 de la Constitución Política de la República, estos limitan el ejercicio de la soberanía e imponen a los órganos del Estado el deber de respetar y promover los derechos humanos en ellos consagrados, configurándose un corpus iuris que, junto a los derechos fundamentales garantizados en la Constitución, busca hacer más efectiva e integral la protección de los derechos humanos. Su plena exigibilidad en el ámbito interno está garantizada por medio de las facultades conservadoras asignadas a los tribunales de justicia con el propósito de velar por la observancia de la Constitución y las leyes, y proveer protección a los derechos fundamentales, las que están establecidas en el artículo 3 del Código Orgánico de Tribunales (COT).

- La decisión de la Corte IDH se sustenta en las potestades jurisdiccionales que tiene para conocer de litigios correspondientes a Estados que han aceptado expresamente su competencia contenciosa, a través de la cláusula facultativa o de admisión prevista en la Convención Americana de Derechos Humanos (CADH) que consta en el artículo 62, CADH.

- El Estado de Chile admitió la jurisdicción de la Corte sin restricciones y, por tanto, está obligado a acatar sus fallos y adoptar todas las medidas administrativas, judiciales y legales para garantizar el pleno cumplimiento de los mismos. A su vez, la Corte IDH tiene competencia ejecutiva para supervisar el cumplimiento de sus sentencias, potestad que es inherente a sus atribuciones jurisdiccionales y permite dar cumplimiento a las obligaciones que, por otra parte, impone el artículo 65 de la $\mathrm{CADH}$, esto es, informar a la Asamblea General de la Organización de Estado Americanos (OEA) sobre el cumplimiento de los fallos pronunciados por el máximo órgano jurisdiccional del Sistema Interamericano de Derecho Humanos de parte de los Estado miembros. 


\section{Capitulo 7. Página 148}

- La observancia del PACTA SUNT SerVANDA de los tratados internacionales y el deber de respetar y promover los derechos consagrados en los tratados internacionales de derechos humanos ratificados por Chile (artículo 5 de la Constitución de la República de Chile), además del reconocimiento del derecho a la tutela judicial efectiva (artículo 19, numeral $3^{\circ}$, inciso $1^{\circ}$ y $5^{\circ}$ de la Constitución ${ }^{231}$ constituyen idóneas bases jurídicas para sostener la existencia de una obligación constitucional de proveer la ejecución de las sentencias de la Corte Interamericana de Derechos Humanos.

- El Estado no puede invocar disposiciones de su ordenamiento jurídico interno como justificación del incumplimiento de un tratado, en virtud del artículo 27 de la Convención sobre derecho de los tratados y sus anexos, suscrita por el Gobierno de Chile en Viena, el 23 de mayo de 1969 promulgado por D.S. 381 de 1981 del Ministerio de Relaciones Exteriores.

- Algunos Estados han cuestionado la ejecutabilidad de sentencias de la Corte IDH que imponen la obligación de dejar sin efecto sentencias condenatorias pronunciadas por los tribunales domésticos, invocando la cosa juzgada. La Corte IDH, en el caso Almonacid Arellano y otros vs. Chile $^{232}$, ha señalado que ello no es aplicable cuando el procedimiento no fue instruido con independencia e imparcialidad, concluyendo que, en ese caso, la sentencia impugnada produce cosa juzgada aparente o fraudulenta, por lo que puede ser anulada sin contravenir dicho principio (Ivanschitz, 2013).

Además de lo expuesto, el debate sobre el cumplimiento de las sentencias internacionales plantea la necesidad de identificar mecanismos judiciales idóneos para dejar sin efecto sentencias condenatorias en sede interna como consecuencia de las sentencias de los tribunales internacionales.

Cabe tener presente que la Corte IDH ha ordenado dejar sin efecto en todos sus extremos sentencias condenatorias en diversos $\operatorname{casos}^{233}$, uno de los cuales también involucró a Chile, como es el Caso Palamara Iribarne vs. Chile ${ }^{234}$. En estos casos se puede observar que los Estados han optado por una diversidad de soluciones jurídicas para dar cumplimiento a estas obligaciones, siendo los más relevantes el caso Tristán Donoso vs. Panamá ${ }^{235}$ y el caso Kimel vs. Argentina ${ }^{236}$. Sin embargo, la solución adoptada por la Corte Suprema en el caso Norin Catriman y otros parece transitar un camino más auspicioso en consonancia con lo que planteamos en este artículo y que implica entender el derecho internacional y el derecho nacional como complementarios y, por tanto, aceptar la jurisdicción de la Corte IDH, garantizando el pleno cumplimiento de sus decisiones jurisdiccionales.

231 Sobre la tutela judicial efectiva, Gonzalo García Pino y Pablo Contreras Vásquez, "El derecho a la tutela judicial y al debido proceso en la jurisprudencia del Tribunal Constitucional chileno", Estudios ConstiTuCIONALES, Año 11, № 2, 2013, pp. 229-282, pp. 244-245.

232 Corte IDH. Caso Almonacid Arellano y otros vs. Chile. Excepciones Preliminares, Fondo, Reparaciones y Costas. Sentencia de 26 de septiembre de 2006. Serie C No. 154., párr. 154.

233 Caso Cantoral Benavides/Perú; Caso Herrera Ulloa/Costa Rica; Caso Palamara Iribarne/Chile; Caso Kimel/Argentina; Caso Tristán Donoso/Panamá; Caso Usón Ramírez/Venezuela y Caso López Mendoza/Venezuela; Caso Bueno Alvez/ Argentina.

234 Corte IDH. Caso Palamara Iribarne vs. Chile. Fondo, Reparaciones y Costas. Sentencia de 22 de noviembre de 2005. Serie C No. 135; Punto resolutivo núm. 12.

235 Corte IDH. Caso Tristán Donoso vs. Panamá. Excepción Preliminar, Fondo, Reparaciones y Costas. Sentencia de 27 de enero de 2009. Serie C No. 193. Párr.2.

236 Corte IDH. Caso Kimel vs. Argentina. Supervisión de Cumplimiento de Sentencia. Resolución de la Corte Interamericana de Derechos Humanos de 5 de febrero de 2013. Visto núm.1. 


\section{Capitulo 7. Página 149}

En primer lugar, ratificó la obligación estatal de cumplimiento, aun a falta de mecanismos internos. El pleno de la Corte Suprema, finalmente, resolvió con fecha 16 de mayo de 2019, que "[...] la ausencia de mecanismo interno que prevea específicamente la fórmula procesal indispensable para ejecutar lo resuelto no inhibe ni excusa a este tribunal de resolver lo pertinente, ya que la mantención del status de incumplimiento que ha sido constatado por la resolución que se ha dictado en la fase de supervisión podría generar nuevas responsabilidades para el Estado de Chile, al tratarse de conductas lesivas de garantías fundamentales y que han sido verificadas por el tribunal internacional competente"237.

A continuación, se pronuncia sobre la complementariedad entre el derecho internacional y el derecho nacional, enfatizando que los derechos fundamentales son condición de legitimidad de las decisiones jurisdiccionales. En efecto, dando cuenta que los derechos vulnerados y sobre los que se pronuncia la Corte IDH en sus sentencia (presunción de inocencia, libertad de pensamiento y expresión, principio de igualdad y no discriminación, el derecho a la igual protección de la ley, derecho a defensa y a recurrir de los fallos penales condenatorios) "[...] tienen su adecuado correlato en nuestro ordenamiento jurídico tanto como garantías tuteladas por la Constitución Política de la República, como bajo la forma de motivos de invalidación de las sentencias y/o los procedimientos instruidos en contravención al debido proceso, presupuesto de legitimidad de una decisión jurisdiccional" 238 .

Finalmente, reconociendo la plena exigibilidad de las sentencias del Corte IDH y ratificando sus funciones jurisdiccionales establecidas en artículos $63 \mathrm{~N}^{\circ} 1$ y $68 \mathrm{~N}^{\circ} 1$ de la Convención Americana de Derechos Humanos, la Corte resuelve optando por una solución respetuosa de derecho internacional, declarando que las sentencias condenatorias adoptadas contra los miembros del Pueblo Mapuche en el caso que se analiza, "han perdido la totalidad de los efectos que le son propios"239.

Transcribimos a continuación la decisión, en este punto, del máximo tribunal chileno para su acertada inteligencia.

Que, por último, esta Corte considera que el único remedio posible de disponer en el caso que se revisa, es declarar que las sentencias condenatorias abordadas por el fallo de la Corte Interamericana de Derechos Humanos han perdido todo efecto, lo cual se constata por las razones de fondo ya invocadas, como asimismo por las medidas que ya se han adoptado por el Estado de Chile en torno a ellas de este caso, el derecho de recurrir de esos fallos penales condenatorios (párrafos 274-291), por lo cual a dichas condenas las califica de arbitrarias e incompatibles con la Convención Americana sobre Derechos Humanos; las sentencias han perdido la totalidad de los efectos que les son $\operatorname{propios}^{240}$ (el destacado es nuestro).

Sin embargo, persiste en el fallo una cierta ambigüedad que se manifiesta en la referencia a la cosa juzgada. Al indicar que la “[...] decisión [...] no importa la invalidación

237 Corte Suprema, Sentencia AD - 13862014, sentencia de 16 de mayo de 2019, párr. 13.

238 Ibídem, párr. 14.

239 Ib., párr. 15.

240 Ib., párr.15. 
de los referidos fallos, atento a los efectos procesales que en el orden nacional se asigna a la nulidad de las resoluciones judiciales, manteniendo la validez de tales sentencias en cuanto a la cosa juzgada, como es la imposibilidad de rever el conflicto que dio origen a los procesos que se revisan"241.

En relación a esta afirmación nos parece relevante precisar las siguientes cuestiones jurídicas: i) la Corte IDH ha determinado que, en el caso, al haberse vulnerado el derecho al debido proceso, lo que se ha configurado es la llamada "cosa juzgada fraudulenta" 242 , la sentencia condenatoria adolece de un vicio de legitimidad al haber vulnerado garantías constitucionales y la Convención Americana de Derechos Humanos, lo que hace inviable su cumplimiento. Esta interpretación es consistente con las consideraciones esgrimidas por la Corte Suprema en los párrafos 13 y 14 de su sentencia; ii) en estas circunstancias, la referencia a la cosa juzgada solo tiene incidencia para efecto de que "no se pueda rever el conflicto" ${ }^{243}$ que motivó el litigio como una salvaguarda de los derechos de las víctimas, pero en caso alguno ello debiera argumentarse como una justificación para eludir el cumplimiento de una obligación internacional, pues ello implicaría vulnerar la Convención Americana de Derechos Humanos y el artículo 27 de la Convención de Viena sobre el Derecho de los Tratados de 1969, que señala lo siguiente: "Una parte no podrá invocar las disposiciones de su derecho interno como justificación del incumplimiento de un tratado" (Noriega y Aguilar, 2019).

\section{Conclusiones}

El análisis de los estándares internacionales en materia de reconocimiento de los derechos

territoriales de los pueblos indígenas, evidencia un importante avance en el derecho internacional y una gran brecha de cumplimiento por parte del Estado de Chile. Dicha brecha de cumplimiento de estándares es más profunda en materia de reconocimiento, demarcación, saneamiento y titulación de tierras indígenas. Diversos organismos han dado cuenta que ello es la causa del conflicto entre el Estado y los pueblos indígenas y motiva la protesta social del Pueblo Mapuche. La criminalización y represión que ejerce el Estado de Chile respecto del Pueblo Mapuche como respuesta a sus deman das territoriales, ha motivado que el Estado incurra en responsabilidad internacional y que haya sido condenado por la Corte IDH. Además, es causa de reiteradas interpelaciones por los organismos internacionales de protección de derecho humanos. Pese al rezago que se observa en Chile en materia de derechos territoriales de pueblos indígenas, no cabe duda de que el derecho internacional ha permitido ampliar el decálogo de los derechos indígenas exigibles en Chile y, consecuencialmente, imponer al Estado de Chile el cumplimiento de las obligaciones contraídas en el ámbito internacional respecto a estos pueblos. La respuesta de la Corte Suprema para resolver las cuestiones jurídicas que impone la exigibilidad de las sentencias internacionales en materia de derechos humanos, referida al caso Norin Catriman y otros vs. Chile, constituye un gran avance

241 Ib., párr. 15.

242 Corte IDH. Caso Almonacid Arellano y otros vs. Chile. Excepciones Preliminares, Fondo, Reparaciones y Costas.

Sentencia de 26 de septiembre de 2006. Serie C No. 154. párr. 154.

243 Corte Suprema Sentencia AD-1386-2019, párr. 15. 


\section{Capitulo 7. Página 151}

en la perspectiva de afianzar la necesaria complementariedad del derecho internacional y el derecho nacional de un modo consistente con un Estado de Derecho que se erige en el respeto de los derechos fundamentales de las personas y los pueblos.

\section{Bibliografía}

AYLWIN, J., MEZA - LOPEHANDIA, M. y YÁÑEZ, N. (2013). Los Pueblos Indigenas y el Derecho. Editorial Lom. Santiago, Chile.

CORREA, M., MOLINA, R. y YÁÑEZ, N. (2005). La Reforma Agraria y las Tierras Mapcube. Lom, Santiago. 470 p.

DONOSO, S. (2017). "Compra de predios en conflicto. Análisis crítico y una propuesta”. En: Aninat, Isabel, Verónica Figueroa y Ricardo González (Eds.) El Pueblo Mapuche en el siglo XXI. Propuestas para un nuevo entendimiento entre culturasen Chile. Centro de Estudios Público, Santiago. Pp. 293-342.

GARCÍA PINO, G.y CONTRERAS VÁSQUEZ, P. (2013). "El derecho a latutela judicial y al debido proceso en la jurisprudencia del Tribunal Constitucional chileno", Estudios Constitucionales, Año 11, No2, 2013, pp. 229-282, pp. 244-245.

IVANSCHITZ, B. (2013). "Un estudio sobre el cumplimiento y ejecución de las sentencias de la Corte Interamericana de Derechos Humanos por el Estado de Chile”, Estudios Constitucionales, Año 11, No 1, 2013, pp. 275-332. ISSN 0718-0195 Centro de Estudios Constitucionales de Chile Universidad de Talca. Disponible [en línea] https://scielo.conicyt.cl/pdf/estconst/v11n1/art08.pdf. Consultada el 8 de mayo de 2020.

NORIEGA, H. y AGUILAR, G. (2019). "Nuevamente la Corte Suprema respetuosa del derecho internacional de los derechos humanos". Disponible [en línea] https://www. diarioconstitucional.cl/articulos/casonorin-catriman-nuevamente-la-corte-supre- ma-respetuosa-del-derecho-internacional-de-los-derechoshumanos/ Consultada el 8 de mayo de 2020.

YÁÑEZ, N. (2017a). Encuesta "Los mapuche rurales y urbanos 2016": un análisis desde el enfoque de derechos indígenas". En: El Pueblo Mapuche en el siglo XXI. Propuestas para un nuevo entendimiento entre culturas en Chile. Isabel Aninat S., Ricardo González T., Verónica Figueroa Huencho, Eds., CEP, Santiago Chile. Disponible [en línea] https:// www.cepchile.cl/cep/libros/libros-digitales/el-pueblo-mapuche-enel-siglo-xxi-pro-puestas-para-un-nuevo. Consultado el 8 de mayo de 2020.

(2017b). "Políticas públicas y su influencia en el reconocimiento y ejercicio de una ciudadanía plena e intercultural al Pueblo Mapuche en Chile". Revista Anales de la Universidad de Chile. Núm. 13 (2017): serie 7, Editora Faride Zerán. Disponible [en línea] https://anales.uchile.cl/index.php/ANUC/issue/view/4828. Consultada el 8 de mayo de 2020.

(2020). "Caso Lhaka Honaht: los avances del Sistema Interamericano de Derechos Humanos". Debates Indígenas. Disponible [en línea] https://debatesindigenas.org/ notas/42-avances-del-sistemaderechos-humanos.html. Consultada el 8 de mayo de 2020. 


\section{Cronología}

\begin{tabular}{|c|c|c|}
\hline Fecha & Acontecimiento & Descripción \\
\hline $\begin{array}{l}21 \text { de diciembre de } \\
2018\end{array}$ & $\begin{array}{lrr}\text { La } & \text { Corte IDH notificó } \\
\text { la resolución } & \text { de } \\
\text { supervisión } & \text { del } \\
\text { cumplimiento } & \text { de } & \text { la } \\
\text { sentencia } & \text { Norín } \\
\text { Catrimán y } & \text { otros } & \text { vs. } \\
\text { Chile } & & \end{array}$ & $\begin{array}{l}\text { La Corte IDH declara que el Estado de Chile } \\
\text { ha dado cumplimiento parcial a la medida de } \\
\text { reparación en relación con dejar sin efecto en } \\
\text { todos sus extremos, las sentencias penales } \\
\text { condenatorias emitidas en contra de las ocho } \\
\text { víctimas del caso. Instó al Estado de Chile } \\
\text { para que adopte todas las medidas judiciales, } \\
\text { administrativas o de cualquier índole para } \\
\text { cumplir con los aspectos pendientes de } \\
\text { cumplimiento. }\end{array}$ \\
\hline $\begin{array}{l}5 \text { de febrero } \\
\text { de } 2019\end{array}$ & 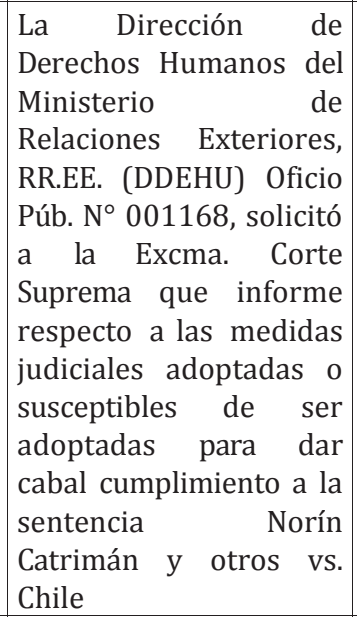 & $\begin{array}{l}\text { La problemática jurídica planteada fue } \\
\text { determinar si un fallo de la Corte IDH puede } \\
\text { dejar sin efecto, esto es anular en todos sus } \\
\text { extremos, los fallos de los tribunales } \\
\text { superiores de justicia de los países miembros } \\
\text { del sistema, en este caso Chile. }\end{array}$ \\
\hline 16 de mayo de 2019 & $\begin{array}{l}\text { Corte Suprema, } \\
\text { Sentencia AD - } 1386- \\
\text { 2014, sentencia de } 16 \\
\text { de mayo de 2019. }\end{array}$ & $\begin{array}{l}\text { La Corte resuelve (párr. 13, } 14 \text { y 15) que la } \\
\text { ausencia de un mecanismo interno que } \\
\text { prevea específicamen te la fórmula procesal } \\
\text { indispensable para ejecutar lo resuelto no } \\
\text { inhibe ni excusa a la Corte Suprema de } \\
\text { resolver lo pertinente; se pronuncia sobre la } \\
\text { complementariedad entre el derecho } \\
\text { internacional y el derecho nacional, } \\
\text { enfatizando que los derechos fundamentales } \\
\text { son condición de legitimidad de las decisiones } \\
\text { jurisdiccionales; y, finalmente, resuelve } \\
\text { optando por una solución respetuosa de } \\
\text { derecho internacional, declarando que las } \\
\text { sentencias condenatorias adoptadas contra } \\
\text { los miembros del Pueblo Mapuche en el caso } \\
\text { que se analiza, "han perdido la totalidad de } \\
\text { los efectos que le son propios". }\end{array}$ \\
\hline
\end{tabular}


Capitulo 7. Página 153

\begin{tabular}{|c|c|c|}
\hline 25 de junio de 2019 & $\begin{array}{l}\text { Informe del Grupo de } \\
\text { Trabajo sobre el } \\
\text { Examen Periódico } \\
\text { Universal Chile, Adición, } \\
\text { Observaciones sobre las } \\
\text { conclusiones y/o } \\
\text { recomendaciones, } \\
\text { compromisos } \\
\text { voluntarios } \\
\text { respuestas del Estado } \\
\text { examinado } \\
\text { (A/HRC/41/6/Add.1.) }\end{array}$ & $\begin{array}{l}\text { Se insta al Estado a "[a]bstenerse de aplicar la } \\
\text { Ley Antiterrorista en el contexto de protestas } \\
\text { sociales de los pueblos mapuche que buscan } \\
\text { reclamar sus derechos". Chile no acepta la } \\
\text { recomendación (número 125.241), } \\
\text { argumentando que "[e]l proyecto de ley que } \\
\text { modifica la legislación antiterrorista nacional } \\
\text { no contempla crear excepciones a la } \\
\text { generalidad desu aplicación" (párr.35). }\end{array}$ \\
\hline
\end{tabular}

